\title{
Hydrometallurgical Recovery of Rare Earth Elements from Mine Tailings and WEEE
}

\author{
S. Peelman ${ }^{1}$ (1) - D. Kooijman ${ }^{2} \cdot$ J. Sietsma ${ }^{1} \cdot$ Y. Yang ${ }^{1}$
}

Published online: 21 May 2018

(C) The Author(s) 2018

\begin{abstract}
The present study proposes three distinct processes to recycle rare earth elements (REE) from two low-grade secondary resources: REE-containing mine tailings and ferrous scrap from shredded waste of electrical and electronic equipment (WEEE). The first developed process extracts both REE and phosphorus from the apatite mineral contained within the mine tailings by way of acidic leaching, followed by cryogenic crystallization and solvent extraction to purify both the REE and P products. This process successfully recovers $70-100 \%$ of the REE from the apatite and over $99 \%$ of its P. The second developed process is a low-cost, efficient method to recover Nd from the ferrous scrap of shredded WEEE. This is achieved by a water corrosion step followed by acidic leaching and precipitation. The overall $\mathrm{Nd}$ recovery of this approach is over 90\%. The final process recovers both the Nd and the Fe from the shredded WEEE scrap. This is done by smelting the shredded WEEE scrap prior to leaching to produce metallic Fe- and a Nd-rich slag. The recovery rates of both $\mathrm{Nd}$ and $\mathrm{Fe}$ are over $90 \%$ and minimal waste is produced; however, the energy consumption is considerable.
\end{abstract}

Keywords WEEE recycling - Low-grade resources - Rare earth elements - Tailings recycling - Secondary resources · Rare earth recycling

\section{Introduction}

The 2010 and 2014 reports on the EU most-critical raw materials $[1,2]$ have shown that the rare earth elements (REEs) have the highest supply risk among all critical materials. These 17 elements (15 lanthanides, Y, and Sc) have great importance in modern day technology, with applications in the fields of electronics [e.g., capacitors (La), flat screen displays (Y, Eu, and $\mathrm{Tb}$ ), and high-strength permanent magnets (Nd, Pr, Dy and Sm)], chemical industry [e.g., catalysts (Ce, $\mathrm{La}$ and $\mathrm{Nd})$ ], and green energy [e.g., batteries (La) and windmills (Nd, Dy, Pr)].

The contributing editor for this article was Vladimiros G. Papangelakis.

S. Peelman

s.peelman@tudelft.nl

1 Department of Materials Science and Engineering, Delft University of Technology, Mekelweg 2, 2628 CD Delft, The Netherlands

2 Elemetal BV, Petroleumweg 32-D, 3196 KD Vondelingenplaat, The Netherlands
The supply risk of REEs originates from a lack of domestic production in Europe, due to the absence of easily exploitable high-grade deposits [3] and the environmental impact [4] that is associated with traditional REE mining and refining. This has resulted in a dependency on imports from China to meet the EU's REE demand. However, due to the instability of the REE market [5], the EU is now considering methods to secure a domestic supply of REE to act as a buffer to market fluctuations and to partially alleviate its dependency on Chinese REE imports. One of the methods that is being considered is the recycling of REE-containing waste streams.

Initial steps have already been taken, and technologies to recycle some specific REE waste streams have been successfully developed (e.g., lamp phosphors [6] and scrap magnets [7]). However, these streams, while having a high REE content, represent only a small fraction of the REEs present in the waste material. They also need to be collected separately and dismantled, which leads to complicated logistics and additional costs. Other, more voluminous waste streams need to be considered for recycling in order to recover a sufficient amount of REEs for the EU. 
The REEcover project [8] was started to evaluate the potential of two high-volume REE-containing waste streams: iron ore mine tailings from the Luossavaara-Kiirunavaara Aktiebolag (LKAB) [9] mine in Kiruna, Sweden, and shredded Waste Electrical and Electronic Equipment (WEEE) from INDUMETAL RECYCLING, Spain [10]. The present study will explore and characterize these two potential waste streams, as well as show several processes that were developed during the REEcover project to recycle these waste streams and recover the REE present within them.

The process developed to recycle the mine tailings is based on the Norsk Hydro process [11] and aims to recover both the REEs and the phosphorous, also a critical raw material, contained within the tailings. The developed process uses $\mathrm{HNO}_{3}$ to dissolve the tailings and produce a solution of impure $\mathrm{H}_{3} \mathrm{PO}_{4}$ and dissolved REE. This solution is then processed with solvent extraction to produce high-grade $\mathrm{H}_{3} \mathrm{PO}_{4}$ and REEs.

Two different processes were developed for the shredded WEEE: a hydrometallurgical approach and a hydrometallurgical approach combined with pyrometallurgical preprocessing. The hydrometallurgical process is based on previous magnet recycling research, where magnet scrap is first roasted and then leached to selectively dissolve the REEs [12]. However, in our proposed process, instead of roasting, water-based corrosion is used to oxidize the iron fraction of the WEEE, in order to save energy and minimize environmental impact. After oxidation, the material is leached with diluted $\mathrm{H}_{2} \mathrm{SO}_{4}$ to extract the REEs, followed by a precipitation treatment with $\mathrm{Na}_{2} \mathrm{SO}_{4}$ to recover the REEs as double sulfates.

The pyro-hydrometallurgical process was developed to preserve the metallic iron within the scrap. This process was designed in collaboration with our project partners at the Norwegian University of Science and Technology (NTNU) for the pyrometallurgical preprocessing and with Elemetal, Netherlands, for the solvent extraction as part of the hydrometallurgical processing. It uses the extremely high oxygen affinity of the REEs to separate them from $\mathrm{Fe}$, without oxidizing the Fe. By using an iron bath, all elements less noble than $\mathrm{Fe}$ are oxidized and transferred to the slag, while $\mathrm{Fe}$ and the more noble elements form a metallic alloy. The produced slags are then leached using $\mathrm{HNO}_{3}$ to extract the REEs, followed by solvent extraction with D2EPHA to extract the REEs from the leach liquor. Finally, the REEs are recovered as oxalates from the solvent extraction strip liquor using precipitation.

\section{Characterization of the Waste Streams}

\section{Mine Tailings}

Exploration of the tailings pond at LKAB, Sweden has shown the presence of REE minerals in the tailings. With a REE concentration of 1200-1500 ppm and an annual tailings production of 8 Mtons, the LKAB iron ore mine has the potential of producing 15 ktons of REEs per year, without considering the 50-100 Mtons of tailings already present in the tailings pond. This makes this waste stream one of the largest potential REE resources in Europe.

The REEs in the tailings have been traced to two minerals: monazite and apatite. Monazite is REE phosphate, $\operatorname{REE}\left(\mathrm{PO}_{4}\right)$, and is one of the primary ores from which REEs are extracted in primary metallurgical industry [13]. It is primarily known for its high content of light REEs (e.g., Ce and La). However, its concentration in the tailings is quite low, approx. $2100 \mathrm{ppm}$. Apatite is a Ca-based phosphate mineral, $\mathrm{Ca}_{5}\left(\mathrm{PO}_{4}\right)_{3} \mathrm{~F}$, which has also been reported to carry REE. However, unlike monazite, which is a REE-based mineral, the apatite only contains trace amounts of REEs. Because REEs have similar properties to $\mathrm{Ca}$, it is possible for REE atoms to occasionally displace a $\mathrm{Ca}$ atom from an apatite lattice site, which results in the apatite mineral to contain trace amounts of REEs [14]; this is denoted as $(\mathrm{Ca}, \mathrm{REE})_{5}\left(\mathrm{PO}_{4}\right)_{3} \mathrm{~F}$. Apatite represents approximately $6 \mathrm{wt} \%$ of the tailings.

These minerals are both phosphates and they can be upconcentrated from the tailings by means of flotation. Our REEcover project partners at Luleå University of Technology (LTU) have performed the necessary flotation trials [15] in order to produce an upgraded concentrate of apatite and monazite suitable for recycling and recovery. The chemical composition of this upgraded concentrate of the tailings is shown in Table 1. Based on the chemical composition and $\mathrm{x}$-ray diffraction (XRD) analysis, the main

Table 1 Concentration of the main elements (in wt\%) and REEs (in ppm) in the upgraded apatite concentrate

\begin{tabular}{lcccccccc}
\hline \multicolumn{7}{l}{ Concentration of main elements (wt\%) and REEs (ppm) } \\
\hline $\mathrm{Ca}$ & $\mathrm{P}$ & $\mathrm{F}$ & $\mathrm{Fe}$ & $\mathrm{Mg}$ & $\mathrm{Si}$ & $\mathrm{Al}$ & \multicolumn{2}{c}{ Total REE } \\
\hline 37.6 & 15.7 & 1.99 & 1.15 & 0.84 & 0.59 & 0.29 & 5300 & \\
\hline $\mathrm{La}$ & $\mathrm{Ce}$ & $\mathrm{Pr}$ & $\mathrm{Nd}$ & $\mathrm{Sm}$ & $\mathrm{Eu}$ & $\mathrm{Gd}$ & $\mathrm{Tb}$ \\
\hline 903 & 2047 & 239 & 906 & 148 & 19.1 & 138 & 16.2 \\
\hline $\mathrm{Y}$ & $\mathrm{Dy}$ & $\mathrm{Ho}$ & $\mathrm{Er}$ & $\mathrm{Tm}$ & $\mathrm{Yb}$ & $\mathrm{Lu}$ & \\
\hline 664 & 101 & 17.3 & 54.1 & 5.3 & 38.3 & 4.00 & \\
\hline
\end{tabular}

${ }^{\mathrm{a} O x y g e n}$ makes up the balance 
component of the upgraded concentrate is identified as apatite, specifically $\mathrm{Ca}_{5}\left(\mathrm{PO}_{4}\right)_{3} \mathrm{~F}$, at a fraction of $80 \mathrm{wt} \%$. Calcite, dolomite, quartz, and magnetite were also detected in minor amounts. The monazite is estimated to have a REE concentration between 4000 and 5000 ppm [16].

\section{Shredded WEEE}

When evaluating a general WEEE stream, the main REE component that can be traced consists of REE magnet particles such as $\mathrm{NdFeB}$ and $\mathrm{SmCo}$. The NdFeB magnets are the most common, and they represent the main REE component that is found in the WEEE stream of INDUMETAL, Spain. As these particles are obviously ferromagnetic, they segregate to the ferrous fraction of a WEEE shredder. Evaluation of all shredded fractions of INDUMETAL's shredder [17] shows that $83 \%$ of the REEs are present in its ferrous fraction, with the other $17 \%$ distributed over various fine and dust fractions. As such the ferrous shredder fraction serves as the most promising fraction for REE recycling as it is rich in REEs as well as poor in other valuable elements, such as $\mathrm{Cu}$, compared to other scrap fractions.

However, as the magnet particles are physically attached to the steel pieces, their recovery is challenging. As such, a prior demagnetization of the ferrous WEEE is required to achieve the necessary separation during physical upgrading. Demagnetization is achieved by heating the ferrous WEEE to $500{ }^{\circ} \mathrm{C}$ for $1 \mathrm{~h}$. After thermal demagnetization, the materials were ground and sieved. $\mathrm{NdFeB}$ magnets are brittle, and thus they break easily, and the fragments are contained in the fine fractions of the sieving operation. Demagnetization and upgrading were done by our partners at LTU [17] to produce a ready-to-use input material with a particle size of less than $75 \mu \mathrm{m}$, required for metallurgical REE recovery. The elemental concentrations of the input material are given in Table 2 .

Table 2 Elemental concentrations of main elements in upgraded ferrous WEEE

\begin{tabular}{lccccccc}
\hline \multicolumn{6}{l}{ Concentration of elements in upgraded ferrous WEEE $(w t \%)^{\mathrm{a}}$} \\
\hline $\mathrm{Fe}$ & $\mathrm{Zn}$ & $\mathrm{Mn}$ & $\mathrm{Ca}$ & $\mathrm{Cu}$ & $\mathrm{Ni}$ & $\mathrm{Si}$ \\
\hline 58 & 7.45 & 3.12 & 2.44 & 2.02 & 1.16 & 1.00 \\
\hline $\mathrm{Nd}$ & $\mathrm{Al}$ & $\mathrm{Pb}$ & $\mathrm{Mg}$ & $\mathrm{Pr}$ & $\mathrm{Sm}$ & $\mathrm{Dy}$ \\
\hline 0.99 & 0.55 & 0.54 & 0.26 & 0.16 & 0.07 & 0.03
\end{tabular}

$\overline{{ }^{a} \text { Oxygen and carbon (leftover plastics) make up the remaining } 22}$ wt $\%$

\section{Hydrometallurgical Processing of an Upgraded Apatite Concentrate}

In order to successfully recycle the mine tailings, all its components must be considered, not just the REEs. Since the primary mineral of the upgraded concentrate is apatite, which is one of the main resources of phosphorous, a process was developed that has its roots in $\mathrm{H}_{3} \mathrm{PO}_{4}$ production. The Norsk Hydro $\mathrm{HNO}_{3}$ process serves as the inspiration for this recycling process, as traditional $\mathrm{H}_{3} \mathrm{PO}_{4}$ production processes using $\mathrm{H}_{2} \mathrm{SO}_{4}$ leaching are not effective due to REE losses to the $\mathrm{CaSO}_{4}$ waste stream [18].

The developed process to recover REEs from the upgraded apatite-rich concentrate follows the flowsheet shown in Fig. 1. The three step process is designed to recover both the phosphorous and the REE present within the concentrate through a sequence of acid leaching, $\mathrm{Ca}$ crystallization and solvent extraction.

The first part of the process is the acid leaching, where the apatite concentrate is digested in a $65 \mathrm{wt} \% \mathrm{HNO}_{3}$ solution. The leaching process was performed in a $1 \mathrm{~L}$ glass leaching tank equipped with an overhead paddle stirrer. The process is run at $60-70{ }^{\circ} \mathrm{C}$ for $6 \mathrm{~h}$ and a liquid/solid $(\mathrm{L} / \mathrm{S})$ ratio of 2 is used to maximize the amount of $\mathrm{Ca}$ recovered in the cryogenic crystallization step of the process.

There are two main reactions taking place during the acid leaching process: the apatite reacts with $\mathrm{HNO}_{3}$ via

$$
\begin{aligned}
& (\mathrm{Ca}, \mathrm{REE})_{5}\left(\mathrm{PO}_{4}\right)_{3} \mathrm{~F}+10 \mathrm{HNO}_{3} \\
& \quad \rightarrow(5-x) \mathrm{Ca}\left(\mathrm{NO}_{3}\right)_{2}+x \mathrm{REENO}_{3}+3 \mathrm{H}_{3} \mathrm{PO}_{4}+\mathrm{HF} \uparrow
\end{aligned}
$$

Note that since the REEs in the apatite are only present in trace amounts $(x \ll 1)$, they do not influence the stoichiometry of the reaction.

The monazite reaction is

$$
(\mathrm{REE}) \mathrm{PO}_{4}+3 \mathrm{HNO}_{3} \rightarrow(\mathrm{REE})\left(\mathrm{NO}_{3}\right)_{3}+\mathrm{H}_{3} \mathrm{PO}_{4}
$$

These reactions yield a leach liquor which is a solution of $\mathrm{H}_{3} \mathrm{PO}_{4}$ and dissolved $\mathrm{Ca}$ and REE, as well as some other impurities, as nitrates.

Under these process conditions $98 \%$ of the apatite concentrate is dissolved, resulting in a near total $(>99 \%)$ phosphorous recovery, in the form of $\mathrm{H}_{3} \mathrm{PO}_{4}$. The REE recovery is not high, with a total combined REE recovery ratio of only $43 \%$. The recovery ratio is defined as

$R=\frac{\mathrm{mREE}_{\text {leach }}}{\text { mREE }_{\text {Concentrate }}} \times 100$

with $\mathrm{mREE}_{\text {leach }}$ the mass of REE leached into the leach liquor and $\mathrm{mREE}_{\text {Concentrate }}$ the mass of the REE present in the concentrate before leaching. Analysis of the limited amount of residue after leaching shows that monazite 
Fig. 1 Proposed recycling flowsheet for the Kiruna mine tailings. The process steps highlighted by the dashed box are the focus of this study

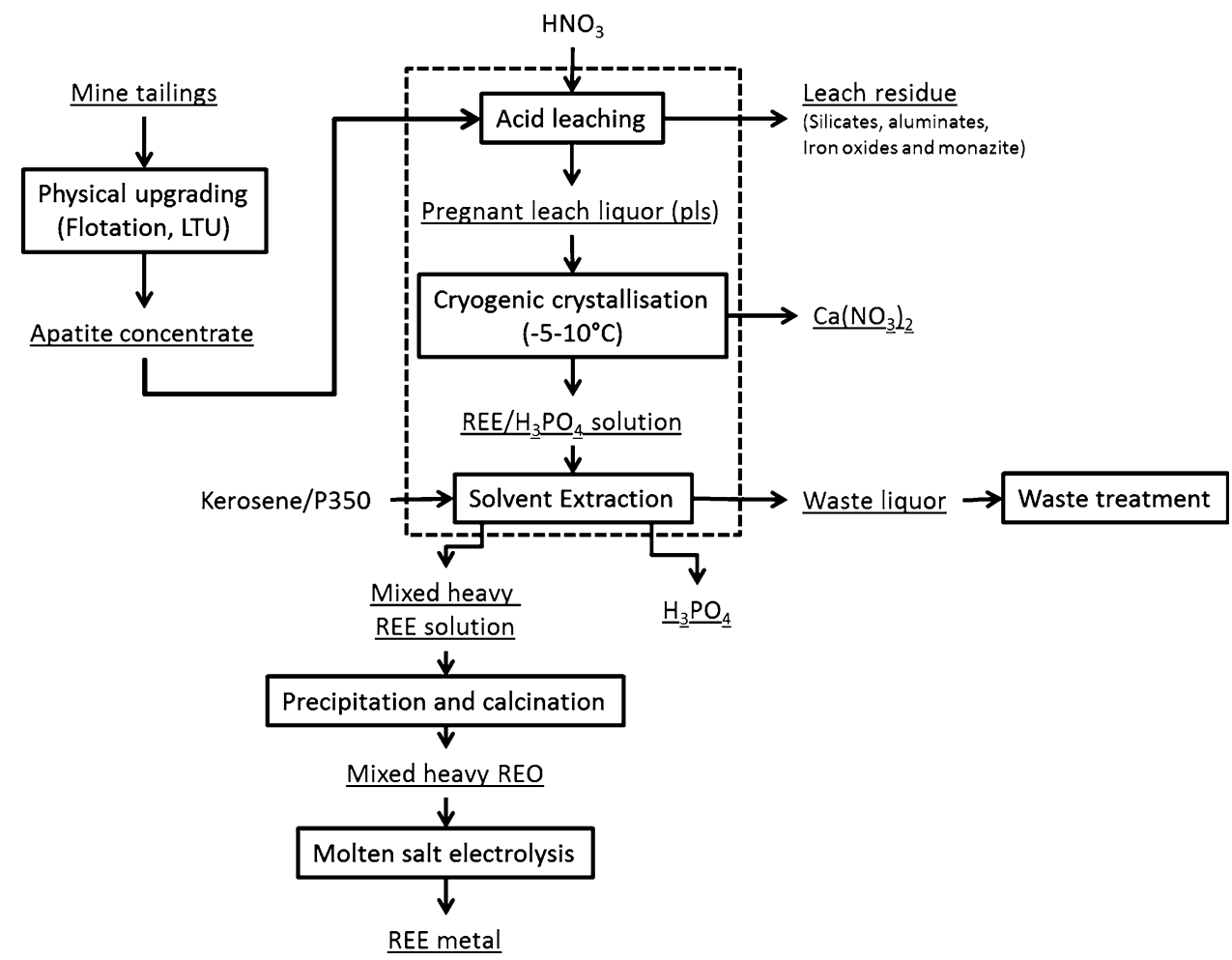

hardly dissolves, which is one of the reasons for the low REE recovery. However, when the total REE recovery is broken down into the recovery ratios of the individual REE (see Table 3), it can be seen that the heavier and more valuable REEs (Y, Dy, Er, ...) have a much higher recovery ratio $(70-100 \%)$ than the lighter REEs (Ce, $\mathrm{La}, \ldots$ ), which have recovery ratios of $26-47 \%$.

The difference in recovery ratios between the heavy and light REEs is due to the nature of the REE-bearing minerals in the apatite concentrate. Whereas the light REEs are associated primarily with monazite, the heavier REEs are associated with apatite where they are present as trace elements. Monazite resists dissolution under the given leaching conditions [16], which translates to low recovery ratios for the lighter REEs. However, the heavier REEs codissolve with the apatite, which under the given leaching conditions fully dissolves.

It should be noted that a large excess (over 50\%) of acid is required to achieve these high extraction ratios for the heavy REE. REE have a high affinity toward $\mathrm{PO}_{4}{ }^{3-}$ and will form insoluble phosphates according to

$$
\mathrm{REE}^{3+}+\mathrm{PO}_{4}^{3-} \rightarrow(\mathrm{REE}) \mathrm{PO}_{4}
$$

Thus, the $\mathrm{pH}$ of the leach solution must be low enough to suppress the dissociation of the formed $\mathrm{H}_{3} \mathrm{PO}_{4}$ that is formed due to the dissolution of the apatite, hence a large excess of $\mathrm{HNO}_{3}$ is required during the leaching process.

Finally consideration must be given to the treatment of the residue of the leaching step. This residue contains the undissolved monazite (approx. $10 \mathrm{wt} \%$ of the residue), with its associated light REEs, and a mixture of insoluble silicates and aluminates. Currently the light REE have a lower demand than the heavier ones, but as the REE market is still unpredictable this residue's value should not be dismissed. If properly stockpiled, this residue can lead to a future high-grade light REE resource.

The second part of the process is the cryogenic crystallization, which removes the majority of the $\mathrm{Ca}$ from the
Table 3 Recovery ratios of the individual REEs after $\mathrm{HNO}_{3}$ leaching of the upgraded apatite concentrate

\begin{tabular}{lccccccc}
\hline \multicolumn{7}{l}{ Recovery ratios of individual REEs $(\%)$ by apatite concentrate leaching } \\
\hline $\mathrm{La}$ & $\mathrm{Ce}$ & $\mathrm{Pr}$ & $\mathrm{Nd}$ & $\mathrm{Sm}$ & $\mathrm{Eu}$ & $\mathrm{Gd}$ & $\mathrm{Tb}$ \\
\hline 37.8 & 26.1 & 45.2 & 46.9 & 59.3 & 66.5 & 68.3 & 73.2 \\
\hline $\mathrm{Y}$ & $\mathrm{Dy}$ & $\mathrm{Ho}$ & $\mathrm{Er}$ & $\mathrm{Tm}$ & $\mathrm{Yb}$ & $\mathrm{Lu}$ & \\
\hline 73.6 & 79.1 & 89 & 75.9 & 100 & 80.6 & 100 \\
\hline
\end{tabular}


pregnant leach liquor as $\mathrm{Ca}\left(\mathrm{NO}_{3}\right)_{2}$. Ca is the main impurity element in the system and must be removed from both the $\mathrm{H}_{3} \mathrm{PO}_{4}$ and the REEs. This is done by cooling the solution to a temperature between -5 and $-10{ }^{\circ} \mathrm{C}$, which causes the $\mathrm{Ca}\left(\mathrm{NO}_{3}\right)_{2}$ to crystallize. A small amount of seed crystals are required to initiate the crystallization, removing $65 \%$ of the $\mathrm{Ca}$ from the pregnant leach solution in $24 \mathrm{~h}$. Analysis of the formed crystals shows that the crystals only contain minimal traces of $\mathrm{P}$ and are free of REEs. $\mathrm{Ca}\left(\mathrm{NO}_{3}\right)_{2}$ is a useful byproduct that has uses in fertilizers, waste water treatment and cooling brines [19].

The final step of this process is the solvent extraction, in which the REEs are recovered from the $\mathrm{H}_{3} \mathrm{PO}_{4}$ solution. This has the additional benefit of purifying the $\mathrm{H}_{3} \mathrm{PO}_{4}$ solution, yielding another valuable product stream. The organic phase of the solvent extraction uses $\mathrm{P} 350, \mathrm{CH}_{3}$ $\mathrm{P}(\mathrm{O})\left(\mathrm{OC}_{8} \mathrm{H}_{17}\right)_{2}$, as an extractant and kerosene as the solvent [20]. The solvent extraction presented in this paper is still in development and the results shown here serve as a proof of concept. In order to show the robustness of the method, the solvent extraction was performed on the leach liquor before the cryogenic Ca removal.

The extraction reaction between the REEs and P350 is

$$
\mathrm{REE}^{3+}+3 \mathrm{NO}_{3}^{-}+3 \mathrm{P} 350 \rightarrow \operatorname{REE}\left(\mathrm{NO}_{3}\right)_{3} \bullet 3(\mathrm{P} 350),
$$

where the REEs react with $\mathrm{P} 350$ and $\mathrm{NO}_{3}{ }^{-}$in a 1:3 ratio.

In order to successfully extract the REE, the $\mathrm{H}_{3} \mathrm{PO}_{4}$ leach liquor is first neutralized with $\mathrm{NH}_{4} \mathrm{OH}$ to a $\mathrm{pH}$ of 0.4 and mixed with $\mathrm{KNO}_{3}$ as a salting agent. $\mathrm{NH}_{4} \mathrm{OH}$ was utilized as neutralization agent, as this is the one used by Norsk Hydro [11] during the production of NPK fertilizers. If pure $\mathrm{H}_{3} \mathrm{PO}_{4}$ is preferred, $\mathrm{Ca}(\mathrm{OH})_{2}$ is a viable alternative.

The solvent extraction trials were run at room temperature and used an agitation rate of $800 \mathrm{rpm}$ for $6 \mathrm{~h}$. Afterward, the solutions were left to settle overnight. To determine the effectiveness of the salting agent, trials were run with and without a salting agent. In order to show the effectiveness of the solvent extraction, the concentrations of the main elements before and after extraction were compared, and the extraction ratios were calculated after the single step of extraction. The concentrations of the main elements before extraction are shown in Table 4.

Only 4 REEs are monitored for the solvent extraction process, as the extraction behavior of the REEs is almost identical.

Table 4 Concentrations of the main elements (ppm) of the prepared solution before solvent extraction

\begin{tabular}{llllllll}
\hline $\mathrm{Ca}$ & $\mathrm{PO}_{4}{ }^{3-}$ & $\mathrm{Fe}$ & $\mathrm{Mg}$ & $\mathrm{Ce}$ & $\mathrm{Nd}$ & $\mathrm{Y}$ & $\mathrm{Dy}$ \\
\hline 51900 & 47700 & 357 & 776 & 121 & 62 & 71 & 10 \\
\hline
\end{tabular}

The solvent extraction trials were run with varying amounts of aqueous leach liquor, organic solvent and extractant. The optimal single step results were obtained when running the extraction with 1:3-1:4 aqueous:organic $(\mathrm{A}: \mathrm{O})$ ratio $($ organic $=$ solvent + extractant $)$, and a $1: 2$ aqueous:extractant (A:E) ratio. The extraction ratios obtained at these conditions can be seen in Table 5 .

The use of a salting agent improves not only the extraction rates of the REEs, but also those of the impurities.

The REE-loaded organic phases were then stripped with a $0.01 \mathrm{M} \mathrm{HNO}_{3}$ solution. The stripping rations can be seen in Table 6.

The use of a salting agent has an adverse effect on the stripping behavior, as the stripping rates of all elements are reduced when using a salting agent.

The final concentrations of each element in the stripping solution can be seen in Table 7 .

When combining single -stage extraction and stripping, a final extraction ratio for each element is obtained as can be seen in Table 8 .

From these results, the optimal extraction and stripping condition found during the trial was an A:O of 1:4 and an A:E of 1:2 without using a salting agent. This yields a REE stream with minimal impurities. Based on these results, a multistage solvent extraction process can be developed to separate and recover the REE from the $\mathrm{H}_{3} \mathrm{PO}_{4}$ solution with little loss to the $\mathrm{PO}_{4}{ }^{3-}$. This method also shows good selectivity toward $\mathrm{Ca}$ separation, even at high $\mathrm{Ca}$ concentrations, meaning that, even though only $65 \mathrm{wt} \%$ of the $\mathrm{Ca}$ can be removed during cryogenic precipitation, this does not negatively impact the subsequent process steps, as even without the Ca removal, the solvent extraction process is capable of recovering the REE.

\section{Hydrometallurgical Extraction of REE from Upgraded Ferrous WEEE}

The shredded WEEE is quite different from the mine tailings: there is only one main REE (Nd) and three trace ones (Pr, Dy, and Sm), and there is little-to-no additional value contained in the ferrous WEEE product streams besides the Nd. The REE-bearing components (NdFeB magnet fragments) are also far more reactive than those in the tailings (monazite).

The main challenge in recycling this ferrous WEEE stream is the copious amount of $\mathrm{Fe}$ it contains (58 wt\% of the stream), which is very reactive but has little-to-no value. This means that any coextracted $\mathrm{Fe}$ negatively affects the purity of the recovered REEs and reduces the viability of the process. As such, the developed processes are designed to minimize the coextraction of $\mathrm{Fe}$ and maximize $\mathrm{Fe}-\mathrm{Nd}$ separation. To realize this goal, two 

of a single-step P350 solvent extraction upon varying solvent and extractant to aqueous ratios (resp. A:O and A:E)
Table 5 Extraction ratios (\%)

\begin{tabular}{lcccccccccc}
\hline (A:O) & (A:E) & Salt conc. (\%) & \multicolumn{2}{l}{ Extraction ratio $(\%)$} \\
\cline { 3 - 10 } & & & $\mathrm{Ca}$ & $\mathrm{PO}_{4}{ }^{3-}$ & $\mathrm{Fe}$ & $\mathrm{Mg}$ & $\mathrm{Ce}$ & $\mathrm{Nd}$ & $\mathrm{Y}$ & $\mathrm{Dy}$ \\
\hline $1: 3$ & $1: 2$ & 0 & 6.9 & 2.8 & 7.5 & 0 & 51.8 & 60.2 & 48.1 & 74.3 \\
$1: 3$ & $1: 2$ & 10 & 9.9 & 6.6 & 15.9 & 12.4 & 57.8 & 70.9 & 60.1 & 83.7 \\
$1: 4$ & $1: 2$ & 0 & 11.9 & 9.9 & 4.9 & 0 & 45.5 & 53.3 & 42.2 & 66.8 \\
$1: 4$ & $1: 2$ & 10 & 7.0 & 4.0 & 8.2 & 11.7 & 50.6 & 57.9 & 53.3 & 52.4 \\
\hline
\end{tabular}

\begin{tabular}{lcrrrrrrrrrr}
\hline (A:O) & (A:E) & Salt conc. (\%) & \multicolumn{2}{l}{ Stripping ratio (\%) } \\
\cline { 3 - 10 } & & & $\mathrm{Ca}$ & $\mathrm{PO}_{4}{ }^{3-}$ & $\mathrm{Fe}$ & $\mathrm{Mg}$ & $\mathrm{Ce}$ & $\mathrm{Nd}$ & $\mathrm{Y}$ & $\mathrm{Dy}$ \\
\hline $1: 3$ & $1: 2$ & 0 & 28.9 & 64.0 & 0 & 0 & 100 & 100 & 100 & 76.2 \\
$1: 3$ & $1: 2$ & 10 & 12.6 & 15.7 & 0 & 0 & 88.7 & 84.3 & 81.9 & 66.6 \\
$1: 4$ & $1: 2$ & 0 & 8.1 & 7.7 & 0 & 0 & 99.5 & 100 & 96,3 & 66.9 \\
$1: 4$ & $1: 2$ & 10 & 10.1 & 10.3 & 0 & 0 & 76.0 & 76.4 & 71.4 & 75.9 \\
\hline
\end{tabular}

\begin{tabular}{llccccccccc}
\hline (A:O) & (A:E) & Salt conc. (\%) & \multicolumn{7}{l}{ Final concentrations in stripping solution (ppm) } \\
\cline { 3 - 10 } & & & $\mathrm{Ca}$ & $\mathrm{PO}_{4}{ }^{3-}$ & $\mathrm{Fe}$ & $\mathrm{Mg}$ & $\mathrm{Ce}$ & $\mathrm{Nd}$ & $\mathrm{Y}$ & $\mathrm{Dy}$ \\
\hline $1: 3$ & $1: 2$ & 0 & 1030 & 852 & 0 & 0 & 63.9 & 41.5 & 34.7 & 5.8 \\
$1: 3$ & $1: 2$ & 10 & 614 & 468 & 0 & 0 & 63.2 & 43.5 & 38.0 & 6.0 \\
$1: 4$ & $1: 2$ & 0 & 501 & 361 & 0 & 0 & 55.0 & 42.6 & 29.0 & 4.6 \\
$1: 4$ & $1: 2$ & 10 & 352 & 185 & 0 & 0 & 47.4 & 32.1 & 29.3 & 4.3 \\
\hline
\end{tabular}

Table 6 Stripping ratios (\%) of a single-step P350 solvent extraction using varying solvent and extractant to aqueous ratios (resp. A:O and A:E)

Table 7 Concentrations of elements (ppm) in the end solution after stripping

Table 8 Final extraction ratios (\%) of the combined extraction and stripping of the single -stage solvent extraction process

\begin{tabular}{llclllllllll}
\hline (A:O) & (A:E) & Salt conc. (\%) & \multicolumn{7}{l}{ Final extraction ratios $(\%)$} \\
\cline { 3 - 11 } & & & $\mathrm{Ca}$ & $\mathrm{PO}_{4}{ }^{3-}$ & $\mathrm{Fe}$ & $\mathrm{Mg}$ & $\mathrm{Ce}$ & $\mathrm{Nd}$ & $\mathrm{Y}$ & $\mathrm{Dy}$ \\
\hline $1: 3$ & $1: 2$ & 0 & 1.99 & 1.79 & 0 & 0 & 52.8 & 66.9 & 48.9 & 57.9 \\
$1: 3$ & $1: 2$ & 10 & 1.18 & 0.98 & 0 & 0 & 52.2 & 70,1 & 53.5 & 59.9 \\
$1: 4$ & $1: 2$ & 0 & 0.97 & 0.76 & 0 & 0 & 45.4 & 68.7 & 40.8 & 45.7 \\
$1: 4$ & $1: 2$ & 10 & 0.68 & 0.39 & 0 & 0 & 39.2 & 51.8 & 41.3 & 42.8 \\
\hline
\end{tabular}

processes are developed: a direct hydrometallurgical approach and a hydrometallurgical approach combined with pyrometallurgical preprocessing.

\section{Direct Hydrometallurgical Approach}

Figure 2 shows the proposed flowsheet to recycle REEcontaining WEEE [21], from the shredder to the metallic REE alloy. The process steps developed and described in this study are highlighted by the dashed box. These three process steps are purely hydrometallurgical processes and consist of an oxidation step, a selective acid leach step, and a REE precipitation step. The preceding steps were developed by LTU, as described in the Characterization section. The subsequent steps were further developed by other partners involved in the REEcover project.
The first part of the highlighted process is the oxidation step, where the metallic Fe present within the WEEE is oxidized to its ferric $(3+)$ state. This is achieved by submerging the upgraded ferrous WEEE in water and inducing the Fe to corrode. The oxidation is accelerated by heating the system to $80{ }^{\circ} \mathrm{C}$ and bubbling additional $\mathrm{O}_{2}$ through the oxidation tank and agitating the mixture under mechanical stirring at $600 \mathrm{rpm}$. Under these conditions, it is possible to oxidize $93 \%$ of the Fe present in $24 \mathrm{~h}$. It should be noted that the oxidation of $\mathrm{Fe}$ is exothermic, so with a properly insulated reactor no external heating is required to achieve these temperatures. This process is made possible due to the fine particle size obtained from grinding and sieving during the physical upgrading. By having a material with a particle size below $75 \mu \mathrm{m}$, the normally slow corrosion process is accelerated to the point where it can be completed within $24 \mathrm{~h}$. 


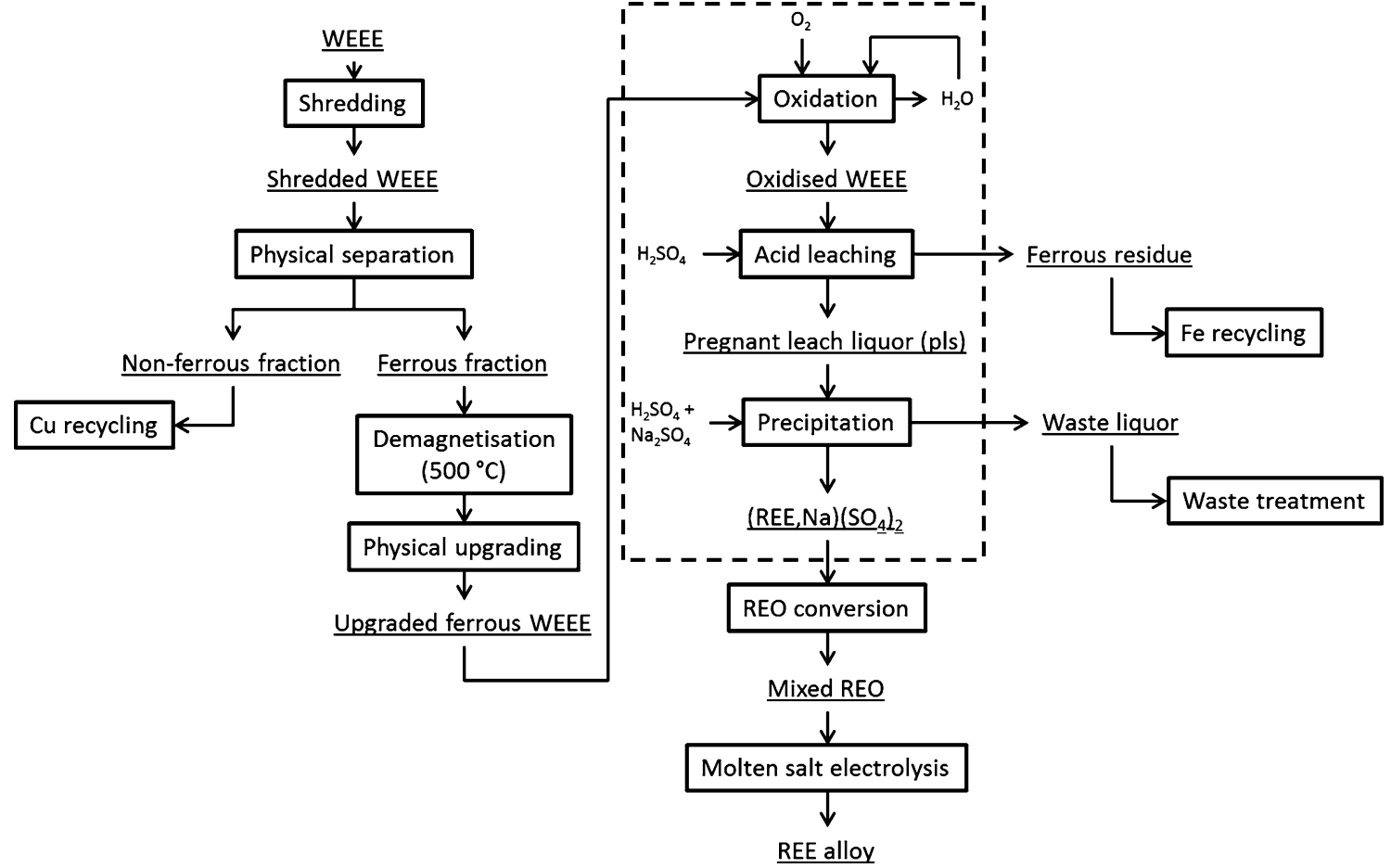

Fig. 2 Proposed flowsheet to recover REE from ferrous WEEE via hydrometallurgy. The process steps highlighted by the dashed box form the focus of this study

The second part of the process is the acidic leaching of the now oxidized WEEE. With the Fe in the oxidized state, its reactivity is decreased and selective leaching of the REEs can be effectuated. The leaching is performed with a solution containing a stoichiometric amount of $\mathrm{H}_{2} \mathrm{SO}_{4}$, as determined by the amount of acid required to the dissolve the nonferrous elements. Based on the chemical composition given in Table 2, this translates to a $3 \% \mathrm{H}_{2} \mathrm{SO}_{4}$ solution. Leaching with this solution at $70{ }^{\circ} \mathrm{C}$ and $\mathrm{L} / \mathrm{S}$ of 5 for 5 min yields the recovery ratios given in Table 9. The resulting leach liquor contains $1.7 \mathrm{~g} / \mathrm{L} \mathrm{Nd}$.

As shown in Table 9, the REE recovery ratios of this step are high, with near-complete recovery of $\mathrm{Nd}$ (the main REE present within the WEEE) and Fe codissolution being less than 20\%. Parametric studies showed that temperature and $\mathrm{L} / \mathrm{S}$ (if the necessary stoichiometric amount of acid is maintained) have little-to-no influence on the obtained

Table 9 Recovery ratios (\%) of elements in the oxidized WEEE after acid leaching for 5 min using $3 \% \mathrm{H}_{2} \mathrm{SO}_{4}$ at $70{ }^{\circ} \mathrm{C}$ and $\mathrm{L} / \mathrm{S}=5$,; note that elements not listed have a recovery rate of $0 \%$

Recovery ratios (\%) of elements oxidized WEEE leaching

\begin{tabular}{llllllll}
\hline $\mathrm{Dy}$ & $\mathrm{Nd}$ & $\mathrm{Pr}$ & $\mathrm{Cu}$ & $\mathrm{Sm}$ & $\mathrm{Fe}$ & $\mathrm{Ca}$ & $\mathrm{Zn}$ \\
\hline 100 & 99.2 & 72.9 & 54.4 & 20.5 & 18.5 & 14.1 & 13.4 \\
\hline
\end{tabular}

recovery ratios. Performing the leaching process at room temperature increases the necessary reaction time to $45 \mathrm{~min}$, but the recovery ratios remain the same. The same is true for the influence of $\mathrm{L} / \mathrm{S}$ : leaching with an $\mathrm{L} / \mathrm{S}$ of 2 instead of 5 at room temperature will increase the reaction speed, but leave the recovery ratios unaffected, assuming the necessary stoichiometric amount if $\mathrm{H}_{2} \mathrm{SO}_{4}$ was supplied. However, considering the heat generated during the oxidation step, a higher temperature is preferred to lowering the $\mathrm{L} / \mathrm{S}$, in order to both save energy and allow the leaching to be performed immediately after the oxidation.

The final part of the process is the REE precipitation step, where $\mathrm{Na}_{2} \mathrm{SO}_{4}$ is used as a precipitation agent to form the double sulfate $(\mathrm{Na}, \mathrm{Nd})\left(\mathrm{SO}_{4}\right)_{2}$ according to

$\mathrm{Na}^{+}+\mathrm{Nd}^{3+}+2 \mathrm{SO}_{4}^{2-} \rightarrow(\mathrm{Na}, \mathrm{Nd})\left(\mathrm{SO}_{4}\right)_{2}$

The precipitation is performed by first re-acidifying the pregnant leach liquor with $\mathrm{H}_{2} \mathrm{SO}_{4}$ to a $\mathrm{pH}$ of no higher than 0.5. This will prevent $\mathrm{Fe}$ contamination during precipitation. A lower $\mathrm{pH}$ is preferred to increase the purity of the obtained precipitates. After re-acidification, $5 \mathrm{~g}$ of $\mathrm{Na}_{2} \mathrm{SO}_{4}$ is added and the solution is kept at $70{ }^{\circ} \mathrm{C}$ for $24 \mathrm{~h}$. The REE recovery of the precipitation process is $92 \%(0.14 \mathrm{~g} / \mathrm{L}$ $\mathrm{Nd}$ left in solution), and the REE and contaminant concentrations of the obtained precipitates are shown in Table 10. No significant concentration of $\mathrm{Fe}$ was measured in the obtained precipitates, which implies that this process has achieved maximum REE/Fe separation. 
Table 10 REE and contaminant concentrations (wt \%) of the obtained $(\mathrm{Na}, \mathrm{REE})\left(\mathrm{SO}_{4}\right)_{2}$ precipitates

\begin{tabular}{|c|c|c|c|c|c|}
\hline \multicolumn{6}{|c|}{ REE and contaminant concentrations (Na, REE) $\left(\mathrm{SO}_{4}\right)_{2}$ in wt $\%$} \\
\hline $\mathrm{Nd}$ & $\operatorname{Pr}$ & Dy & $\mathrm{Ca}$ & $\mathrm{Zn}$ & $\mathrm{Fe}$ \\
\hline 30.3 & 3.11 & 0.39 & 0.88 & 0.28 & 0.00 \\
\hline
\end{tabular}

Linking all these process steps together, an overall $\mathrm{Nd}$ recovery ratio of $91 \%$ can be achieved during this stage of the recycling process. The process consumes a minimal amount of acid, and its energy consumption is limited to what is required to drive the agitators of the reaction vessels. With proper heat management and insulated reactors, no substantial external heating would be required to run this process, since the oxidation process should supply the required heat. Thermodynamic simulation suggests cooling would be required to prevent boiling the solution at an industrial scale.

The main drawback of the purely hydrometallurgical process is the production of $\mathrm{Fe}(\mathrm{OH})_{3} / \mathrm{Fe}_{2} \mathrm{O}_{3}$ ferric leaching residue. This residue could potentially be recycled for its $\mathrm{Fe}$ content; however, there are currently no viable recycling processes for this type of residue. As such, for the moment, this residue is considered as a waste product. To minimize this waste generation, an alternative process was developed, which includes a pyrometallurgical pretreatment. In cooperation with
NTNU, the developed process aims to slag the REEs and other highly reactive elements and also produce a metallic Fe phase, which, unlike the leaching residue, is not a waste product and can be used in iron making. This combined pyro-hydrometallurgical approach is described in the following section.

\section{Hydrometallurgical Approach with Pyrometallurgical Preprocessing}

Figure 3 shows the proposed flowsheet to recycle REEs from WEEE using both pyro- and hydrometallurgical processes, with the process steps discussed in this study being highlighted with the dashed box.

As with the recycling process presented in the flowsheet of Fig. 2, the WEEE is first shredded and separated in a ferrous and nonferrous fraction, however instead of demagnetizing the ferrous fraction, it is smelted to produce a REE-bearing slag and a metallic Fe phase. The smelting process is performed at $1650{ }^{\circ} \mathrm{C}\left( \pm 30{ }^{\circ} \mathrm{C}\right)$ in graphite crucibles, with a small amount of $\mathrm{Na}_{2} \mathrm{~B}_{4} \mathrm{O}_{7}$ flux to ensure fluidity of the slag. After smelting, the slag is separated from the metallic phase and is milled to a particle size of approximately $100 \mu \mathrm{m}$. All smelting experiments were performed by our project partners at NTNU. The milled slags have then been sent to the hydrometallurgical process steps which will be detailed below.

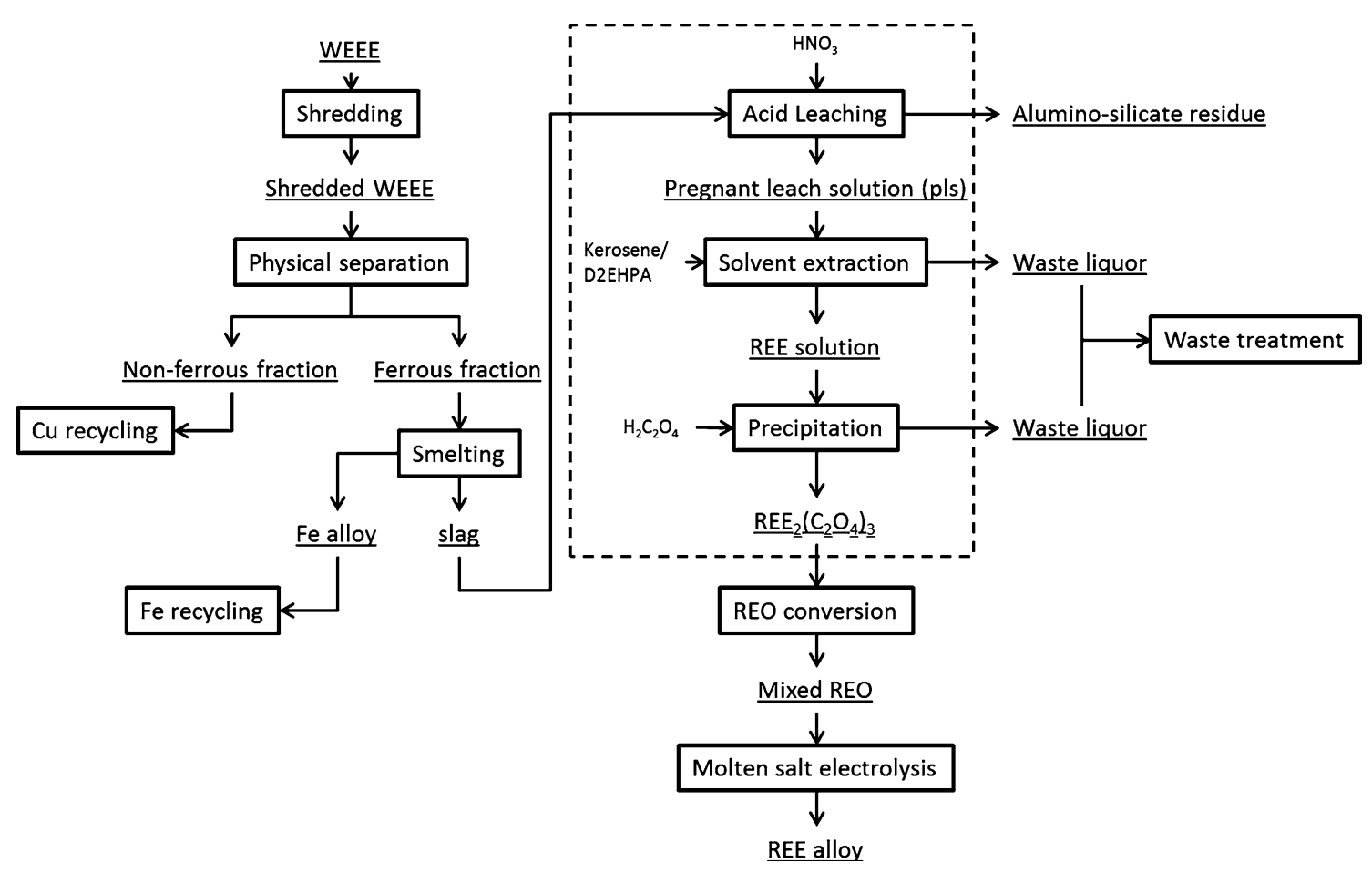

Fig. 3 Proposed flowsheet to recover REE from Ferrous WEEE via a combination of pyro- and hydrometallurgical processes. The process steps highlighted by the dashed box are the focus of this study 
The REE recovery ratio to the slag is above 95\% (REE losses are attributed to improper metal-slag separation and slag inclusions in the metal) and the chemical composition of the obtained slags is shown in Table 11. Due to the nature of the pyrometallurgical process all elements that are less noble than $\mathrm{Fe}$ report to the slag, including any $\mathrm{Al}$ and $\mathrm{Mg}$ present in the WEEE. Note that the ferrous WEEE was not physically upgraded before it was smelted; as such the chemical composition listed in Table 2 is not an accurate representation of the ferrous WEEE that was smelted.

The first hydrometallurgical part of the process is the slag leaching. The slag is leached with diluted $\mathrm{HNO}_{3}$ to dissolve the REE. $\mathrm{HNO}_{3}$ was chosen as the leaching acid for its compatibility with the solvent extraction in the next step. The leaching is performed at $70{ }^{\circ} \mathrm{C}$ for $6 \mathrm{~h}$ using a 8.3 wt $\% \mathrm{HNO}_{3}$ solution at a $\mathrm{L} / \mathrm{S}$ of 5 , which represents only a small stoichiometric excess. Under these conditions the leaching process successfully extracts all REEs from the slags, however several other elements are also coextracted, see Table 12.

$\mathrm{Ca}, \mathrm{Al}$ and $\mathrm{Mg}$ are the main impurities in the leach liquor, as well as trace amounts of $\mathrm{Fe}$ and $\mathrm{Mn}$, after

Table 11 Main elements (excluding O) of the obtained slag after WEEE smelting

\begin{tabular}{|c|c|c|c|c|c|c|c|}
\hline \multicolumn{8}{|c|}{ Main elements (wt\%) in slag } \\
\hline $\mathrm{Al}$ & $\mathrm{Mg}$ & $\mathrm{Ca}$ & $\mathrm{Nd}$ & $\mathrm{Fe}$ & $\operatorname{Pr}$ & Mn & Dy \\
\hline 23.0 & 9.34 & 8.96 & 1.25 & 1.17 & 0.20 & 0.06 & 0.00 \\
\hline
\end{tabular}

leaching. The Fe dissolution can be prevented by subjecting the milled slag to magnetic separation to remove traces of metallic Fe that remain after the separation of the slag and the metal phase. The $\mathrm{Ca}, \mathrm{Al}$ and $\mathrm{Mg}$ coextraction cannot be prevented however, and it forms the main challenge of this process. These two elements are highly reactive in the slag, and their dissolution cannot be suppressed. Their presence in the leach liquor means that solvent extraction is required to separate the REE, as no precipitation agent is sufficiently selective to separate REEs from $\mathrm{Ca}$.

The developed solvent extraction process is shown in Fig. 4. This process was developed in cooperation with Elemetal, the Netherlands [22].

In the solvent extraction process, Di-(2-ethylhexyl)phosphoric acid (D2EHPA) is used as extractant with ShellsolD100 as solvent. In order to achieve the highest extraction efficiency, a large concentration of $500 \mathrm{~g} / \mathrm{L}$ of D2EHPA is used in the organic solution.

Acidic organic extractants like D2EPHA react with metallic cations via

$\mathrm{M}^{3+}+(\mathrm{m}+3) \mathrm{HOrg} \leftrightarrow \mathrm{M}(\mathrm{Org})_{3}(\mathrm{HOrg})_{m}+3 \mathrm{H}^{+}$

where the metallic cation replaces three protons from the organic phase.

Next to a strong affinity for REEs, D2EHPA also has a strong affinity for $\mathrm{Fe}^{3+}$. Thus, in order to remove the traces of $\mathrm{Fe}^{3+}$ in the leach liquor, the $\mathrm{pH}$ of the liquor is increased to 2 by adding $\mathrm{NH}_{4} \mathrm{OH}\left(25 \mathrm{wt} \% \mathrm{NH}_{3}\right)$. In this way, over $99 \%$ of the $\mathrm{Fe}^{3+}$ is precipitated as $\mathrm{Fe}(\mathrm{OH})_{3}$. After filtration, the leachate is fed into a solvent extraction circuit which
Table 12 Recovery ratios (\%) of the main elements and concentration in leach liquor $(\mathrm{g} /$ $\mathrm{L})$ of the slag leaching process

\begin{tabular}{lcccccccc}
\hline & \multicolumn{6}{c}{ Recovery ratios of main elements $(\%)$ and concentration in leach liquor $(\mathrm{g} / \mathrm{L})$ from slag leaching } \\
\cline { 2 - 8 } & $\mathrm{Al}$ & $\mathrm{Mg}$ & $\mathrm{Ca}$ & $\mathrm{Nd}$ & $\mathrm{Fe}$ & $\mathrm{Pr}$ & $\mathrm{Mn}$ & $\mathrm{Dy}$ \\
\hline$(\%)$ & 31.4 & 22.9 & 100 & 100 & 19.5 & 100 & 81.7 & 100 \\
$\mathrm{~g} / \mathrm{L}$ & 14.4 & 4.3 & 17.9 & 2.5 & 0.5 & 0.4 & 0.1 & 0.002 \\
\hline
\end{tabular}

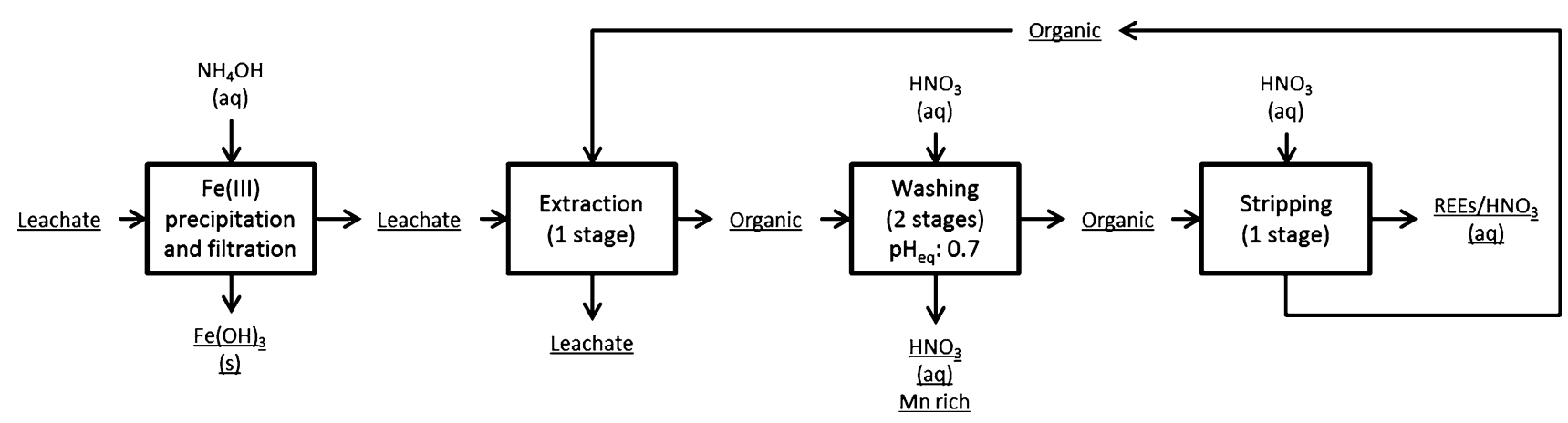

Fig. 4 Solvent extraction process developed with collaboration of Elemetal for the combined pyro- and hydrometallurgical process 
Table 13 Composition of the mixed REOs produced with the demo pyro-hydrometallurgical flowsheet (concentrations measured by ICPMS after dissolution of the mixed REOs in aqua regia, and the oxygen content is calculated by assuming that the REEs are present in the forms as shown in the table)

Composition of the mixed REOs (\%)

\begin{tabular}{llll}
\hline $\mathrm{Nd}_{2} \mathrm{O}_{3}$ & $\mathrm{Pr}_{6} \mathrm{O}_{11}$ & $\mathrm{Dy}_{2} \mathrm{O}_{3}$ & Total \\
\hline 81.5 & 9.03 & 3.61 & 94.2 \\
\hline
\end{tabular}

contained 1 extraction stage, 2 wash stages, and 1 stripping stages.

Of the elements which are shown in Table 12, only the REEs, $\mathrm{Ca}$, and $\mathrm{Mn}$ are extracted from the leach liquor into the organic solution, $\mathrm{Al}$ and $\mathrm{Mg}$ are not extractable under these conditions. However, both $\mathrm{Ca}$ and $\mathrm{Mn}$ can be removed from the organic phase by implementing two washing stages before stripping. The $\mathrm{pH}$ of the aqueous phase which is leaving the final wash stage $\left(\mathrm{pH}_{\mathrm{eq}}\right)$ is controlled to a value of 0.7 . A lower $\mathrm{pH}$ results in a loss of REEs and a higher $\mathrm{pH}$ results in a less-efficient removal of $\mathrm{Ca}$ and $\mathrm{Mn}$. Once the $\mathrm{Ca}$ and $\mathrm{Mn}$ are removed from the organic phase, the REEs can be stripped using a $35 \mathrm{wt} \%$ $\mathrm{HNO}_{3}$ solution, so that a pure REE solution is obtained.

At a final step of the process, the REEs are recovered in a solid form through precipitation. A stoichiometric amount of oxalic acid is added to the pure REE solution resulting from the stripping stage of the solvent extraction circuit. This results in the precipitation of REE oxalates, which are subsequently calcined in order to produce REOs. The compositions of the rare earth oxide mixtures are shown in Table 13. The total composition of the oxides does not add up to $100 \%$. This can be explained by residual carbon and nitrogen, which are not removed during calcination. By increasing the calcination temperature and/or the residence time in the calcination furnace, these elements can be completely removed. A trace amount of Mn is present in the final oxides, but its concentration does not exceed $500 \mathrm{ppm}$.

\section{Concluding Remarks}

The present study proposes three distinct processes that can be used to recycle REEs from low-grade secondary resources. For the recycling of REE-containing mine tailings, a three-stage process was developed, which utilizes $\mathrm{HNO}_{3}$ leaching, cryogenic crystallization, and solvent extraction using P350 and kerosene to extract the valuable heavy REE from the apatite contained within the tailingsas well as to produce a purified $\mathrm{H}_{3} \mathrm{PO}_{4}$ solution, $\mathrm{Ca}\left(\mathrm{NO}_{3}\right)_{2}$ salt, and a high-grade monazite residue as valuable byproducts. The current leaching efficiencies attained for this process are $70-100 \%$ for the heavy REE (Y, Dy, $\mathrm{Er}, \ldots$ ) and over $99 \%$ for P. The cryogenic crystallization recovers $65 \%$ of the $\mathrm{Ca}$ as $\mathrm{Ca}\left(\mathrm{NO}_{3}\right)_{2}$, and the proof-ofconcept solvent extraction can separate approx. $50 \%$ of the REE from the leach liquor in a single stage. With multiple stages, achieving a more successful separation of REEs can be expected.

For the recycling of REE from shredded ferrous WEEE, two processes were developed, each with a specific focus. The first process was focused on extracting the REEs from the shredded WEEE with high cost effectiveness. This was achieved through a process that utilizes a water corrosion step, followed by a diluted $\mathrm{H}_{2} \mathrm{SO}_{4}$ leaching, and finally a precipitation step using $\mathrm{Na}_{2} \mathrm{SO}_{4}$. This process requires no external heating and consumes only a limited amount of chemicals. The $\mathrm{Nd}$ is recovered as $(\mathrm{Na}, \mathrm{Nd})(\mathrm{SO} 4)_{2}$ precipitates with only minor $\mathrm{Ca}$ contamination, and the overall recovery ratio of $\mathrm{Nd}$ is $91 \%$. The major drawback of this process is the $\mathrm{Fe}(\mathrm{OH})_{3}$ waste generation.

The second developed process for recycling REE from shredded WEEE aims to prevent the generation of $\mathrm{Fe}(\mathrm{OH})_{3}$ waste and instead produce metallic Fe scrap metal. This is achieved by first smelting the WEEE to produce a metallic $\mathrm{Fe}$ phase and a REE-rich slag. The $\mathrm{Fe}-\mathrm{Nd}$ separation achieved by this process is over $99 \%$. The obtained slags are then leached with diluted $\mathrm{HNO}_{3}$ to extract the REE form the slags. This leaching process extracts all of the REEs from the slags, and these REEs are subsequently recovered from the leach liquor by D2EPHA solvent extraction. After solvent extraction, the REE are recovered as oxalates through oxalic acid precipitation. The overall recovery ratio of $\mathrm{Nd}$ of this process is $90 \%$. This process works around the production of $\mathrm{Fe}(\mathrm{OH})_{3}$ waste and also produces recyclable scrap Fe. However, the high energy consumption (700 kWh/ton) does create an economic barrier. The necessity of running a solvent extraction process to purify the REE also reduces the economic feasibility.

Acknowledgements The authors acknowledge the financial support under the EU Project FP7 REEcover (Project ID: 603564). The authors also thank their project partners at INDUMETAL RECYCLING, Spain, for providing the ferrous WEEE input material; the Luleå University of Technology, Sweden for providing and physically upgrading both the tailings and the WEEE; NTNU, Norway for providing the slags of the smelted WEEE; and Elemetal for conducting the solvent extraction of the leached slags. The authors thank R. Hendrikx at the Department of Materials Science and Engineering of the Delft University of Technology for analysis and XRD characterization, and M. van den Brink at the Department of Process \& Energy of the Delft University of Technology for ICP-OES analysis.

Open Access This article is distributed under the terms of the Creative Commons Attribution 4.0 International License (http://creative commons.org/licenses/by/4.0/), which permits unrestricted use, 
distribution, and reproduction in any medium, provided you give appropriate credit to the original author(s) and the source, provide a link to the Creative Commons license, and indicate if changes were made.

\section{References}

1. European Commission Enterprise and Industry (2010) Critical raw materials for the EU Report of the Ad hoc Working Group on defining critical raw materials

2. European Commission Enterprise and Industry (2014) Report on Critical Raw Materials for the EU Report of the Ad hoc Working Group on defining critical raw materials

3. Goodenough KM et al (2016) Europe's rare earth element resource potential: an overview of REE metallogenetic provinces and their geodynamic setting. Ore Geol Rev 72(Part 1):838-856. https://doi.org/10.1016/j.oregeorev.2015.09.019

4. Sonich-Mullin C, Reisman D, Weber R (2012) Rare earth elements a review of production, processing, recycling and associated environmental issues. United States Environmental Protection Agency, Washington, D.C

5. Naumov AV, Russ AV (2008) Review of the world market of rare-earth metals. J. Non-ferrous Metals 49(1):14-22. https://doi. org/10.1007/s11981-008-1004-6

6. Otto R, Wojtalewicz-Kasprzak A (2012) Method for recovery of rare earths from fluorescent lamps. US20120027651 A1

7. Lyman JW, Palmer GR (1993) Recycling of neodymium iron boron magnet scrap. U.S. Department of the Interior, Bureau of Mines, Washington, D.C

8. REEcover http://www.reecover.eu/

9. LKAB https://www.lkab.com/en/

10. Indumetal recycling http://www.indumetal.com/

11. Nielsson FT (1987) Manual of fertilizer processing. Marcel Dekker Inc., New York

12. Tanaka M, Oki T, Koyama K, Narita H, Oishi T (2013) Chapter 255-recycling of rare earths from scrap. In: Jean-Claude GB,
KP Vitalij (eds) Handbook on the physics and chemistry of rare earths, vol 43. Elsevier, Oxford, pp 159-211. https://doi.org/10. 1016/b978-0-444-59536-2.00002-7

13. Krishnamurthy N, Gupta CK (2005) Extractive metallurgy of rare earths. CRC Press, Boca Raton, FL

14. Bandara MTS, Senanayake G (2015) Leachability of rare-earth, calcium and minor metal ions from natural Fluorapatite in perchloric, hydrochloric, nitric and phosphoric acid solutions: effect of proton activity and anion participation. Hydrometallurgy 153:179-189. https://doi.org/10.1016/j.hydromet.2015.02.002

15. Pålsson B, Martinsson O, Wanhainen C, Fredriksson A (2014) Unlocking rare earth elements from European apatite-iron ores. 1st European Rare Earth Resources Conference (ERES 2014), Milos (Greece), 4-7 September 2014, pp. 211-220

16. Peelman S, Sun ZHI, Sietsma J, Yang Y (2016) Hydrometallurgical extraction of rare earth elements from low grade mine tailings. In Alam S, Kim H, Neelameggham NR, Ouchi T, Oosterhof H (eds) Rare metal technology, Springer, Cham. https://doi.org/10.1007/978-3-319-48135-7_2

17. Pålsson B, Wanhainen C (2015) Recovery of rare earth elements from electronic waste by cryo-grinding. In: Conference in Minerals Engineering 2015, Luleå, pp. 65-79

18. Habashi F (1985) The recovery of the Lanthanides from phosphate rock. J Chem Technol Biotechnol 35A:5-14. https://doi. org/10.1002/jctb.5040350103

19. Laue W, Thiemann M, Scheibler E, Wiegand KW (2000) Nitrates and nitrites. Ullmann's encyclopedia of industrial chemistry. Wiley-VCH Verlag GmbH \& Co. KGaA, Weinheim

20. Li H, Guo F, Zhang Z, Li D, Wang Z (2006) A new hydrometallurgical process for extracting rare earths from apatite using solvent extraction with P350. J Alloys Compd 408-412:995-998. https://doi.org/10.1016/j.jallcom.2004.12.119

21. Peelman S, Sietsma J, Yang Y (2018) Recovery of Neodymium as $(\mathrm{Na}, \mathrm{Nd})(\mathrm{SO} 4) 2$ from the ferrous fraction of a general WEEE shredder stream. J Sustain Metall. https://doi.org/10.1007/ s40831-018-0165-5

22. Elemetal BV. http://www.elemetal.eu/ 